\title{
EFEKTIVITAS PROMOSI KESEHATAN TERHADAP PENGETAHUAN DAN SIKAP TATALAKSANA DIARE PADA BALITA DI KOTA PALOPO
}

\author{
Musdalifah $^{1}$, Irmayanti A.Oka ${ }^{2}$, Marwanty ${ }^{3}$ \\ Prodi DIII Kebidanan, STIKES Kurnia Jaya Persada Palopo ${ }^{1,2}$ \\ Puskesmas Wara Utara Kota ${ }^{3}$ \\ musdalifah.epidui@gmail.com ${ }^{1}$, irmayantioka89@gmail.com²
}

\begin{abstract}
Knowledge and attitudes of mothers about home-based management of toddler diarrhea are predisposing factors that are considered globally to reduce morbidity and mortality due to diarrhea. This study aims to see the effectiveness of health promotion through leaflets, audiovisuals, discussion, and demonstration towards knowledge and attitude of mothers about home-based management of toddler diarrheaA quasi-experimental design was conducted in September-October 2020 in Palopo City. A total 120 samples were taken by a purposive sampling technique. The data was collected using a and then analyzed using the Wilcoxon test, Kruskal Wallis, and Mann-Whitney. There were significant differences in knowledge and attitude scores before and after the intervention using leaflets, audiovisual, discussion, and simulation (P-value for all of group were $<0.05)$. There was a significant difference in knowledge scores between the leaflet vs audiovisual; leaflets vs discussions; leaflets vs demonstrations; audiovisual vs discussion $(P<0.05)$ with the highest mean score on the audiovisual group. Whereas, in the comparison of audiovisual vs demonstration $(P=0.150)$ and discussion vs demonstration $(P=0.292)$ there was no significant difference. No significant difference in the increase in attitude scores between the four groups after the intervention $(P=0.107)$. Effect of health promotion by leaflet, audiovisual, discussion, and demonstration towards respondents knowledge were significant difference, but that effect not significant towards respondents attitude.
\end{abstract}

Keywords : Attitude, Health Promotion, Home-Based Diarrhea Management, Knowledge, Toddlers

\begin{abstract}
ABSTRAK
Pengetahuan dan sikap ibu tentang tatalaksana balita diare di tingkat rumah tangga merupakan faktor predisposisi yang direkomendasikan secara global untuk mengurangi angka kesakitan dan kematian balita karena diare. Penelitian ini bertujuan untuk mengetahui efektivitas penyuluhan melalui leaflet, audiovisual, diskusi dan demonstrasi terhadap pengetahuan dan sikap ibu tentang tatalaksana balita diare di rumah tangga. Penelitian ini dilaksanakan pada bulan september-oktober 2020 di Kota Palopo dengan menggunakan quasi-experimental design dengan pendekatan pre-test post-test. Sampel sebanyak 120 responden dipilih dengan teknik purposive sampling. Pengambilan data dilakukan dengan menggunakan kuesioner .Analisis data menggunakan uji nonparametrik Wilcoxon, Kruskall Wallis dan Mann-Whitney. Ada perbedaan skor pengetahuan dan sikap yang signifikan sebelum dan setelah intervensi tatalaksana diare balita di rumah tangga dengan menggunakan leaflet, audiovisual, diskusi dan demonstrasi $(\mathrm{p}<0,05)$. Berdasarkan perbedaan peningkatan skor pre-test post-test, ada perbedaan peningkatan skor pengetahuan yang signifikan diantara keempat perlakuan $(\mathrm{p}=0,000)$. Perbandingan skor pengetahuan antara leaflet vs audiovisual; leaflet vs diskusi; leaflet vs demonstrasi; audiovisual vs diskusi masing-masing berbeda secara bermakna $(\mathrm{p}<0,05)$ dengan nilai mean skor paling tinggi pada audiovisual. sedangkan pada perbandingan audiovisual vs demonstrasi $(p=0,150)$ dan diskusi vs demonstrasi $(\mathrm{p}=0,292)$ tidak ada perbedaan signifikan. Tidak ada perbedaan signifikan pada peningkatan skor sikap diantara keempat kelompok $(\mathrm{p}=0,107)$. Efek promosi kesehatan menggunakan leaflet, audiovisual, diskusi dan demonstrasi dapat meningkatkan pengetahuan responden secara signifikan tetapi tidak signifikan terhadap sikap responden.
\end{abstract}

Kata Kunci : Balita, Pengetahuan, Promosi Kesehatan, Sikap, Tatalaksana Diare Rumah Tangga 


\section{PENDAHULUAN}

Diare, sebagaimana yang dilaporkan oleh badan kesehatan dunia (2017), masih menjadi penyebab kedua kematian balita secara global yaitu sekitar 525.000 balita setiap tahun.(World Health Organization, 2017) Di Indonesia, angka prevalensi dan insidensi diare balita masih terus berfluktuasi. Pada tahun 2018, prevalensi nasional diare pada balita berdasarkan gejala dan diagnosis tenaga kesehatan sekitar 12,3\%. Pada tahun yang sama, prevalensi diare balita di Provinsi Sulawesi Selatan tercatat sekitar 11,8\%.(Kemenkes Republik Indonesia, 2019) Lebih dari itu, dalam Laporan Profil Kesehatan Indonesia tahun 2019, diare bahkan dinobatkan menjadi penyebab nomor satu (sekitar $10,7 \%$ ) kematian balita melebihi angka kematian karena pneumonia (sekitar 9,5\%).(Kemenkes RI, 2020)

Salah satu upaya pemerintah untuk mengurangi angka kejadian dan kematian akibat diare yaitu program tatalaksana penderita diare di tatanan rumah tangga dengan lima langkah yaitu rehidrasi, pengobatan dengan zink, pemberian ASI dan makanan tambahan, antibiotik selektif dan pengenalan kasus kegawatdaruratan .(Kemenkes Republik Indonesia, 2011) Berdasarkan laporan Riskesdas (2018), secara nasional, gambaran perilaku keluarga tentang perawatan balita diare masih tergolong rendah, yaitu dengan rincian penggunaan oralit atau larutan gula garam $34,8 \%$ pada tahun 2018 ; pengobatan diare dengan zink sekitar $26,1 \%$ pada tahun 2018.(Kemenkes Republik Indonesia, 2019) Khusus di Provinsi Sulawesi Selatan, penggunaan oralit dan larutan gula garam masih lebih rendah dari angka nasional, yaitu sekitar $25,2 \%$ dan penggunaan zink sekitar 29,3\%.(Kemenkes Republik Indonesia, 2019) Tatalaksana perawatan balita diare seperti penggunaan oralit yang masih rendah bisa jadi disebabkan karena masyarakat masih belum mengetahui bahwa oralit harus diberikan segera setelah anak mengalami diare untuk mencegah kekurangan cairan. Padahal, besar kemungkinan orangtua balita diare dapat melakukan penatalaksanaan diare yang tepat jika mempunyai pengetahuan dan sikap yang baik, sebagaimana hasil penelitian yang dilakukan di Puskesmas Piyungan Bantul Yogyakarta (2016) bahwa ada hubungan yang signifikan antara tingkat pengetahuan ibu dengan penatalaksanaan awal diare'(Rosalia, 2016) Pengetahuan dan sikap manajemen diare ibu balita dapat ditingkatkan dengan memberikan informasi kesehatan.(Zain et al., 2020) Oleh karenanya, upaya transfer pengetahuan kepada ibu, keluarga atau pengasuh balita sebagai bekal dalam penatalaksanaan diare di tatatanan rumah tangga masih harus ditingkatkan.

Proses transfer pengetahuan kepada ibu atau pengasuh balita dapat dilakukan dengan promosi kesehatan. Keberhasilan penyuluhan yang notabenenya merupakan salah satu intervensi kesehatan masyarakat yang paling umum dan mudah dilakukan, sebenarnya sangat tergantung kepada komponen pembelajaran, termasuk metode dan media penyuluhan. Sebagaimana penjelasan Setiawan dan Dermawan (2008) yang disitasi oleh J et al. (2019) bahwa media yang menarik akan memberikan keyakinan, sehingga perubahan pengetahuan, sikap dan perilaku sasaran pendidikan kesehatan dapat dipercepat-( $\mathrm{J}$ et al., 2019) Edgar Dale, dalam teorinya tentang kerucut pengalaman mengatakan bahwa demonstrasi, diskusi, dan audiovisual lebih efektif dibandingkan media verbal/ membaca saja.(Susilowati, 2016)

Sejak beberapa tahun terakhir, diare masih menjadi sepuluh penyakit langganan masyarakat Kota Palopo. Pada tahun 2018 tercatat jumlah kasus diare di Kota Palopo mencapai 3287.(Badan Pusat Statistik Kota Palopo, 2018) Pada studi pendahuluan di 
Puskesmas Wara Utara Kota Palopo diketahui bahwa media promosi yang digunakan adalah leaflet, sedangkan di Puskesmas Pontap diketahui bahwa selama 3 bulan terakhir sejak pandemi Covid-19 dan diberlakukannya pembatasan jam pelayanan puskesmas, maka kunjungan rumah yang biasa dilakukan khusus sebagai tindak lanjut promosi kesehatan terhadap kasus diare yang berobat ke puskesmas juga tidak diadakan. Penelitian ini bertujuan mengidentifikasi efektivitas intervensi dengan membandingkan media leaflet, audiovisual, diskusi dan demonstrasi terhadap pengetahuan, dan sikap ibu tentang tatalaksana diare balita di rumah tangga.

\section{METODE}

Penelitian dilakukan di Kota Palopo pada bulan September-Oktober 2020 dengan menggunakan desain quasiexperimental nonequivalent control group design dengan pendekatan pre-test posttest. Sampel penelitian sebanyak 120 responden yang selanjutnya dibagi menjadi 4 kelompok perlakuan promosi kesehatan terkait tatalaksana diare yaitu kelompok leaflet, kelompok audiovisual, kelompok diskusi dan kelompok demonstrasi. Penelitian ini menggunakan nonprobability sampling jenis purposive sampling dengan kriteria inklusi adalah ibu yang memiliki balita dengan riwayat diare 1 bulan terakhir baik yang didiagnosis oleh dokter/ tenaga kesehatan/ dirawat di pelayanan kesehatan maupun yang dirawat di rumah serta bersedia menjadi responden. Pengumpulan data dilakukan dengan mengunjungi rumah berdasarkan data pasien diare di puskesmas ataupun informasi balita yang kemungkinan diare dalam 4 minggu terakhir baik dari kader, tenaga kesehatan ataupun dari warga setempat dengan menggunakan kuesioner terstruktur yang telah di uji validitas dan reabiltasnya. Materi leaflet, audiovisual, diskusi dan demonstrasi yang diberikan dibuat berdasarkan poin-poin tatalaksana diare rumah tangga atau lintas diare, pengertian dan ciri diare serta cara pencegahannya. Responden yang medapat leaflet diberi 10-15 menit untuk membaca materi. Materi audiovisual diberikan selama 15 menit dengan tambahan kesimpulan 4 menit. Demonstrasi dilakukan kurang lebih 10-15 menit, dan diskusi dilakukan dengan menggunakan rujukan materi leaflet yang tidak dipahami pada media leaflet atau masalah berdasarkan pengalaman dalam melakukan penatalaksanaan balita diare.

Data penelitian diolah dengan menggunakan SPSS25. Hasil analisis uji normalitas data Shapiro-Wilk diperoleh nilai $\mathrm{p}=0,000$ dan pada uji normalitas data nonparametrik dengan KolmogorovSmirnov juga diperoleh nilai $\mathrm{p}<0,05$, sehingga disimpulkan bahwa data penelitian tidak berdistribusi normal dan selanjutnya dianalisis dengan menggunakan uji nonparametrik dengan taraf signifikansi 95\%. Untuk mengetahui ada tidaknya perbedaan antara dua kelompok sampel ini, maka digunakan uji statistik Wilcoxon sebagai penggganti uji paired sample $T$ test. Untuk mengetahui ada tidaknya perbedaan skor pengetahuan dan sikap post-test pada keempat kelompok perlakuan dilakukan uji Kruskal Wallis sebagai pengganti uji ANOVA. Uji Mann-Withney dilakukan sebagai uji lanjutan pengganti uji Post Hoc untuk mengetahui pada kelompok mana saja terjadi perbedaan skor yang signifikan (Priyatno, 2016) 
HASIL

Karakteristik responden

Tabel 1: Karakteristik Responden Berdasarkan Kelompok Perlakuan

\begin{tabular}{|c|c|c|c|c|c|c|c|c|c|c|}
\hline \multirow[t]{2}{*}{ Variabel } & \multicolumn{2}{|c|}{$\begin{array}{c}\text { Leaflet } \\
(n=30)\end{array}$} & \multicolumn{2}{|c|}{$\begin{array}{c}\text { Audiovisual } \\
(\mathbf{n}=\mathbf{3 0})\end{array}$} & \multicolumn{2}{|c|}{$\begin{array}{c}\text { Diskusi } \\
(\mathrm{n}=30)\end{array}$} & \multicolumn{2}{|c|}{$\begin{array}{c}\text { Demonstrasi } \\
(\mathbf{n}=\mathbf{3 0})\end{array}$} & \multicolumn{2}{|c|}{$\begin{array}{c}\text { Total } \\
(\mathbf{n}=\mathbf{1 2 0})\end{array}$} \\
\hline & $\mathbf{F}$ & $\%$ & $\mathbf{F}$ & $\%$ & $\mathbf{F}$ & $\%$ & $\mathbf{F}$ & $\%$ & $\mathbf{F}$ & $\%$ \\
\hline \multicolumn{11}{|l|}{ Umur } \\
\hline$<21$ tahun & 1 & 3,3 & 2 & 6,7 & 3 & 10,0 & 0 & 0,0 & 6 & 5,0 \\
\hline 21-35tahun & 25 & 83,3 & 26 & 86,7 & 24 & 80,0 & 23 & 76,7 & 98 & 81,7 \\
\hline$>35$ tahun & 4 & 13,3 & 2 & 6,7 & 3 & 10,0 & 7 & 23,3 & 16 & 13,3 \\
\hline \multicolumn{11}{|l|}{ Pendidikan } \\
\hline Tinggi & 9 & 30,0 & 1 & 3,3 & 2 & 6,7 & 2 & 6,7 & 14 & 11,7 \\
\hline Menengah atas & 17 & 56,7 & 28 & 93,3 & 28 & 93,3 & 24 & 80,0 & 97 & 80,8 \\
\hline Dasar 9 tahun & 4 & 13,3 & 1 & 3,3 & 0 & 0 & 4 & 13,3 & 9 & 7,5 \\
\hline \multicolumn{11}{|l|}{ Pekerjaan } \\
\hline IRT & 26 & 86,7 & 30 & 100 & 29 & 96,7 & 28 & 93,3 & 113 & 94,2 \\
\hline $\begin{array}{l}\text { Bekerja luar } \\
\text { rumah }\end{array}$ & 4 & 13,31 & 0 & 0 & 1 & 3,3 & 2 & 6,7 & 7 & 5,8 \\
\hline \multicolumn{11}{|l|}{ Pendapatan } \\
\hline$\geq 2$ juta & 6 & 20,0 & 1 & 3,3 & 0 & 0 & 2 & 6,7 & 9 & 7,5 \\
\hline$<2$ juta & 24 & 80,0 & 29 & 96,7 & 30 & 100 & 28 & 93,3 & 111 & 92,5 \\
\hline \multicolumn{11}{|l|}{ Pengalaman } \\
\hline Ya & 24 & 80,0 & 24 & 80,0 & 29 & 96,7 & 21 & 70,0 & 98 & 81,7 \\
\hline Tidak & 6 & 20,0 & 6 & 20,0 & 1 & 3,3 & 9 & 30,0 & 22 & 18,3 \\
\hline \multicolumn{11}{|l|}{ Informasi } \\
\hline $\mathrm{Ya}$ & 22 & 73,3 & 24 & 80,0 & 29 & 96,7 & 25 & 83,3 & 100 & 83,3 \\
\hline Tidak & 8 & 26,7 & 6 & 20,0 & 1 & 3,3 & 5 & 16,7 & 20 & 16,7 \\
\hline
\end{tabular}

Sumber: Data primer, 2020

Berdasarkan tabel 1 diketahui bahwa, dari 120 responden yang kemudian dibagi menjadi 4 kelompok sehingga masingmasing kelompok terdiri dari 30 responden dengan mayoritas responden berusia 21-35 tahun dan $(81,7 \%)$ dan menamatkan pendidikan hingga sekolah menengah atas $(80,8 \%)$. Responden berpendidikan tinggi pada kelompok yang memperoleh leaflet sebanyak 30\% sedangkan pada kelompok audiovisual, diskusi dan demonstrasi masing-masing sebanyak 3,3\%, 6,7\% dan $6,7 \%$. Hampir semua responden adalah ibu rumah tangga $(94,2 \%)$ dengan pendapatan rata-rata keluarga yang $<2$ juta per bulan
$(92,5 \%)$. Sebanyak $81,7 \%$ responden memiliki pengalaman merawat balita diare, dan paling banyak terdapat pada kelompok yang diberi perlakuan diskusi sebanyak 96,7\% responden, sedangkan pada kelompok leaflet, audiovisual dan demonstrasi masing-masing $80 \%, 80 \%$ dan $70 \%$. Sebanyak $83,3 \%$ responden sudah pernah mendapat informasi mengenai tatalaksana balita diare dengan sebaran paling banyak berada di kelompok yang mendapat perlakuan diskusi dan paling sedikit pada kelompok leaflet dengan kisaran masing-masing sebesar $96,7 \%$ dan $73,3 \%$. 


\section{Perbedaan Pengetahuan Dan Sikap Responden Sebelum Dan Setelah Intervensi Berdasarkan Kelompok Perlakuan}

Tabel 2: Hasil Uji Wilcoxon Perbedaan Pengetahuan Dan Sikap Sebelum Dan Setelah Intervensi

\begin{tabular}{|c|c|c|c|c|c|c|c|c|c|}
\hline \multicolumn{2}{|c|}{ Intervensi } & $\mathbf{n}$ & Median & SD & $\begin{array}{l}\text { Min - } \\
\text { maks }\end{array}$ & $\begin{array}{c}(-) \\
\text { rank }\end{array}$ & (+) rank & Ties & $\begin{array}{l}\text { Asymp } \\
\text {.Sig }\end{array}$ \\
\hline \multicolumn{10}{|l|}{ Pengetahuan } \\
\hline \multirow{2}{*}{ Leaflet } & Sebelum & 30 & 9,00 & 2,82 & $1-13$ & \multirow{2}{*}{0} & $\begin{array}{c}27 \\
\text { Mean }=14,0\end{array}$ & \multirow{2}{*}{3} & \multirow{2}{*}{0,000} \\
\hline & Setelah & 30 & 12,50 & 1,20 & $9-13$ & & Sum $=378$ & & \\
\hline \multirow{2}{*}{ Audiovisual } & Sebelum & 30 & 5,00 & 1,69 & $1-8$ & \multirow{2}{*}{0} & $\begin{array}{c}30 \\
\text { Mean }=155\end{array}$ & \multirow[t]{2}{*}{0} & \multirow[t]{2}{*}{0,000} \\
\hline & Setelah & 30 & 10,50 & 1,50 & $7-12$ & & Sum=465 & & \\
\hline \multirow{2}{*}{ Diskusi } & Sebelum & 30 & 4,00 & 2,56 & $1-10$ & \multirow{2}{*}{0} & $\begin{array}{c}30 \\
\text { Mean }=15.5\end{array}$ & \multirow{2}{*}{0} & \multirow{2}{*}{0,000} \\
\hline & Setelah & 30 & 9,00 & 1,72 & $6-13$ & & Sum $=465$ & & \\
\hline \multirow{2}{*}{ Demonstrasi } & Sebelum & 30 & 5,00 & 2,45 & $2-12$ & \multirow{2}{*}{0} & $\begin{array}{c}29 \\
\text { Mean }=150\end{array}$ & \multirow{2}{*}{1} & \multirow{2}{*}{0,000} \\
\hline & Setelah & 30 & 11,00 & 1,23 & $9-13$ & & Sum $=435$ & & \\
\hline \multicolumn{10}{|l|}{ Sikap } \\
\hline \multirow{2}{*}{ Leaflet } & Sebelum & 30 & 55,00 & 7,08 & $45-71$ & \multirow{2}{*}{0} & $\begin{array}{c}29 \\
M e a n=15\end{array}$ & \multirow{2}{*}{1} & \multirow{2}{*}{0,000} \\
\hline & Setelah & 30 & 61,50 & 6,72 & $47-73$ & & Sum $=435$ & & \\
\hline \multirow{2}{*}{ Audiovisual } & Sebelum & 30 & 49,00 & 2,75 & $45-59$ & \multirow{2}{*}{0} & $\begin{array}{c}28 \\
\text { Mean=14,5 }\end{array}$ & \multirow{2}{*}{2} & \multirow{2}{*}{0,000} \\
\hline & Setelah & 30 & 55,50 & 2,72 & $49-64$ & & Sum $=406$ & & \\
\hline \multirow[t]{2}{*}{ Diskusi } & Sebelum & 30 & 51,50 & 4,63 & $44-66$ & \multirow[t]{2}{*}{0} & $\begin{array}{c}28 \\
\text { Mean }=14,5\end{array}$ & \multirow[t]{2}{*}{2} & \multirow[t]{2}{*}{0,000} \\
\hline & Setelah & 30 & 56,00 & 3,96 & $52-67$ & & Sum=406 & & \\
\hline \multirow{2}{*}{ Demonstrasi } & Sebelum & 30 & 50,00 & 4,67 & $42-67$ & \multirow[t]{2}{*}{0} & $\begin{array}{c}29 \\
\text { Mean }=15,0\end{array}$ & \multirow{2}{*}{1} & \multirow[t]{2}{*}{0,000} \\
\hline & Setelah & 30 & 56,00 & 3,81 & $50-72$ & & Sum $=435$ & & \\
\hline
\end{tabular}

Sumber : Data primer, 2020

Berdasarkan tabel 2 diketahui bahwa median skor pengetahuan responden sebelum perlakuan yang paling tinggi yaitu pada kelompok leaflet $(9,00)$, selanjutnya pada kelompok audiovisual dan demonstrasi (masing-masing nilainya 5,00) dan yang paling rendah dengan median 4,00 pada kelompok diskusi. Kelompok yang semua respondennya mengalami peningkatan skor adalah kelompok audiovisual dan diskusi. Berdasarkan hasil uji Wilcoxon, ada perbedaan yang signifikan pada skor pengetahuan sebelum dan setelah pemberian intervensi baik dengan menggunakan leaflet, audiovisual, diskusi maupun demonstrasi $(\mathrm{P}=0,000<0,05)$.

Berdasarkan tabel 2, skor sikap responden sebelum diberikan penyuluhan secara berurut dari kelompok median yang paling tinggi yaitu leaflet $(55,00)$, diskusi $(51,50)$, demonstrasi $(50,00)$ dan yang paling rendah adalah audiovisual $(49,00)$. Perbedaan skor sikap sebelum dan setelah pemberian intervensi baik menggunakan leaflet, audiovisual, diskusi maupun demonstrasi, dan perbedaan skor sebelum dan setelah penyuluhan pada masingmasing kelompok ini berbeda secara bermakna $(\mathrm{P}<0,05)$. 
Perbedaan Skor Pengetahuan Dan Sikap Responden Berdasarkan Nilai Post-Test Tabel 3: Hasil uji Kruskal Wallis perbedaan skor pengetahuan dan sikap responden berdasarkan nilai post-test keempat kelompok perlakuan di Kota Palopo

\begin{tabular}{|c|c|c|c|c|c|c|}
\hline \multirow[b]{2}{*}{ Intervensi } & \multicolumn{3}{|c|}{ Pengetahuan } & \multicolumn{3}{|c|}{ Sikap } \\
\hline & $\mathbf{N}$ & $\begin{array}{l}\text { Mean } \\
\text { Rank }\end{array}$ & Asymp.Sig & $\mathbf{N}$ & $\begin{array}{l}\text { Mean } \\
\text { Rank }\end{array}$ & Asymp.Sig \\
\hline Leaflet & 30 & 89,67 & \multirow{4}{*}{0,000} & 30 & 85,50 & \multirow{4}{*}{0,000} \\
\hline Audiovisual & 30 & 54,60 & & 30 & 45,02 & \\
\hline Diskusi & 30 & 30,58 & & 30 & 52,13 & \\
\hline Demonstrasi & 30 & 67,15 & & 30 & 59,35 & \\
\hline
\end{tabular}

Sumber: Data primer, 2020

Berdasarkan tabel 3 diketahui bahwa ada perbedaan signifikan peringkat rata-rata (mean rank) skor pengetahuan setelah penyuluhan dari yang tertinggi secara berurut adalah pada kelompok leaflet, demonstrasi, audiovisual dan diskusi dengan skor masing-masing yaitu 89,67 ; 67,15 ; 54,60 dan 30,58 dengan nilai $\mathrm{P}=0,000$.

Berdasarkan hasil uji Kruskal Wallis pada tabel 3, ada perbedaan signifikan peringkat rata-rata skor sikap setelah intervensi diberikan dari yang tertinggi secara berurut adalah pada kelompok leaflet, demonstrasi, diskusi dan terakhir audiovisual dengan skor masing-masing yaitu 85,$50 ; \quad 59,35 ; \quad 52,13 ;$ dan 45,02 $\mathrm{P}=0,000$.

Selanjutnya untuk mengetahui pada kelompok mana saja terjadi perbedaan skor pengetahuan dan sikap post-test yang signifikan maka dilakukan uji MannWithney pada tabel 4.

Tabel 4: Hasil Uji Mann-Whitney Perbandingan Skor Pengetahuan Dan Sikap Responden Berdasarkan Nilai Post-Test Pada Dua Kelompok Perlakuan Kota Palopo

\begin{tabular}{|c|c|c|c|c|c|c|}
\hline \multirow[b]{2}{*}{ Intervensi } & \multicolumn{3}{|c|}{ Pengetahuan } & \multicolumn{3}{|c|}{ Sikap } \\
\hline & $\begin{array}{c}\text { Mean } \\
\text { rank }\end{array}$ & $\begin{array}{c}\text { Sum of } \\
\text { Rank }\end{array}$ & $\begin{array}{l}\text { Asymp. } \\
\text { Sig }\end{array}$ & $\begin{array}{c}\text { Mean } \\
\text { rank }\end{array}$ & $\begin{array}{c}\text { Sum of } \\
\text { Rank }\end{array}$ & $\begin{array}{c}\text { Asymp. } \\
\text { Sig }\end{array}$ \\
\hline $\begin{array}{l}\text { Leaflet } \\
\text { Audiovisual }\end{array}$ & $\begin{array}{l}40,07 \\
20,93\end{array}$ & $\begin{array}{r}1202,0 \\
628,0 \\
\end{array}$ & 0,000 & $\begin{array}{l}39,93 \\
21,07\end{array}$ & $\begin{array}{r}1198,0 \\
632,0 \\
\end{array}$ & 0,000 \\
\hline $\begin{array}{l}\text { Leaflet } \\
\text { Diskusi }\end{array}$ & $\begin{array}{l}43,08 \\
17,92 \\
\end{array}$ & $\begin{array}{r}1292,5 \\
537,5 \\
\end{array}$ & 0,000 & $\begin{array}{l}38,62 \\
22,38 \\
\end{array}$ & $\begin{array}{r}1158,5 \\
671,5 \\
\end{array}$ & 0,000 \\
\hline $\begin{array}{l}\text { Leaflet } \\
\text { Demonstrasi }\end{array}$ & $\begin{array}{l}37,52 \\
23,48 \\
\end{array}$ & $\begin{array}{r}1125,5 \\
704,5 \\
\end{array}$ & 0,001 & $\begin{array}{l}37,95 \\
23,05 \\
\end{array}$ & $\begin{array}{r}1138,5 \\
691,5 \\
\end{array}$ & 0,001 \\
\hline $\begin{array}{l}\text { Audiovisual } \\
\text { Diskusi }\end{array}$ & $\begin{array}{l}37,68 \\
23,32\end{array}$ & $\begin{array}{r}1130,5 \\
699,5 \\
\end{array}$ & 0,001 & $\begin{array}{l}28,73 \\
32,27\end{array}$ & $\begin{array}{l}862,0 \\
968,0\end{array}$ & 0,428 \\
\hline $\begin{array}{l}\text { Audiovisual } \\
\text { Demonstrasi }\end{array}$ & $\begin{array}{l}26,98 \\
34,02\end{array}$ & $\begin{array}{r}809,5 \\
1020,5\end{array}$ & 0,108 & $\begin{array}{l}26,22 \\
34,78\end{array}$ & $\begin{array}{r}786,5 \\
1043,5\end{array}$ & 0,053 \\
\hline Diskusi & 20,35 & 610,5 & & 28,48 & 845,5 & \\
\hline Demonstrasi & 40,65 & $\begin{array}{r}1219 \\
5\end{array}$ & 0,000 & 35,52 & 975,5 & 0,364 \\
\hline
\end{tabular}

Sumber : Data primer, 2020

Berdasarkan tabel 4, pada perbandingan skor post-test pengetahuan, leaflet secara signifikan memiliki nilai peringkat rata-rata (mean rank) yang lebih tinggi, baik ketika dibandingkan dengan kelompok audiovisual $(\mathrm{P}=0,000)$, diskusi $(\mathrm{P}=0,000)$ maupun demonstrasi $(\mathrm{P}=0,001)$. Sebaliknya kelompok diskusi selalu memiliki nilai peringkat rata-rata yang lebih rendah jika dibandingkan dengan kelompok lainnya. Perbedaan signifikan juga terjadi pada perbandingan audiovisual Vs diskusi $(\mathrm{P}=0,001)$ dan diskusi Vs demonstrasi $(\mathrm{P}=0,000)$.

Berdasarkan tabel 4, pada perbandingan skor post-test sikap, leaflet 
secara signifikan memiliki nilai peringkat rata-rata (mean rank) yang lebih tinggi, baik ketika dibandingkan dengan kelompok audiovisual $(\mathrm{P}=0,000)$, diskusi $(\mathrm{P}=0,000)$ maupun demonstrasi $(\mathrm{P}=0,001)$. Tidak ada perbedaan signifikan pada perbandingan audiovisual vs diskusi $(\mathrm{P}=0,428)$; audiovisual Vs demonstrasi $(\mathrm{P}=0,053)$; dan diskusi Vs demonstrasi $(\mathrm{P}=0,364)$.

\section{Perbedaan Skor Pengetahuan Dan Sikap Responden Berdasarkan Nilai Selisih Pre-Test - Post-Test}

Tabel 5: Hasil Uji Kruskal Wallis Perbedaan Skor Pengetahuan Dan Sikap Responden Berdasarkan Selisih Skor Pre-Test Post-Test Di Kota Palopo

\begin{tabular}{|c|c|c|c|c|c|c|}
\hline Intervensi & & Peng & uan & & Sil & \\
\hline & $\mathbf{N}$ & $\begin{array}{l}\text { Mean } \\
\text { Rank }\end{array}$ & Asymp.Sig & $\mathbf{N}$ & $\begin{array}{l}\text { Mean } \\
\text { Rank }\end{array}$ & Asymp.Sig \\
\hline Leaflet & 30 & 37,35 & \multirow{4}{*}{0,000} & 30 & 61,35 & \multirow{4}{*}{0,107} \\
\hline Audiovisual & 30 & 79,65 & & 30 & 64,73 & \\
\hline Diskusi & 30 & 58,27 & & 30 & 47,67 & \\
\hline Demonstrasi & 30 & 66,73 & & 30 & 68,25 & \\
\hline
\end{tabular}

Sumber: Data primer, 2020

Berdasarkan tabel 5 diketahui bahwa ada perbedaan yang signifikan selisih skor pengetahuan pre-test post-test setelah penyuluhan tatalaksana balita diare antara kelompok yang diberi leaflet, audiovisual, diskusi dan demonstrasi dengan mean reank secara berurut dari yang tertinggi adalah pada kelompok audiovisual $(79,65)$, demonstrasi $(66,73)$, diskusi $(58,27)$ dan leaflet $(37,35)$ dengan nilai $\mathrm{P}=0,000$.

Berdasarkan tabel 5 diketahui bahwa tidak ada perbedaan yang signifikan selisih skor sikap pre-test post-test setelah penyuluhan tatalaksana balita diare antara kelompok yang diberi leaflet, audiovisual, diskusi dan demonstrasi dengan mean reank secara berurut dari yang tertinggi adalah kelompok demonstrasi $(68,25)$, audiovisual $(64,73)$, leaflet $(61,35)$ dan diskusi $(47,67)$ dengan nilai $\mathrm{P}=0,107$.

Untuk mengetahui pada perbandingan kelompok mana saja terjadi perbedaan skor pengetahuan yang signifikan, maka dilakukan uji Mann-Withney sebagaimana yang tertera pada tabel 6 .

Tabel 6: Hasil Uji Mann-Whitney Perbandingan Skor Pengetahuan Antar Dua Kelompok Perlakuan Berdasarkan Selisih Nilai Pre-Test- Post-Test Kota Palopo

\begin{tabular}{lcrc}
\hline \multicolumn{1}{c}{ Intervensi } & Mean rank & Sum of Rank & Asymp. Sig \\
\hline Leaflet & 20,28 & 608,5 & \multirow{2}{*}{0,000} \\
Audiovisual & 40,72 & 1221,5 & \multirow{2}{*}{0,009} \\
\hline Leaflet & 24,65 & 739,5 & \multirow{2}{*}{0,002} \\
Diskusi & 36,35 & 1090,5 & \multirow{2}{*}{0,010} \\
\hline Leaflet & 23,42 & 702,5 & \multirow{2}{*}{0,150} \\
Demonstrasi & 37,58 & 1127,5 & \multirow{2}{*}{0,292} \\
\hline Audiovisual & 36,23 & 743,0 & \\
Diskusi & 24,77 & 1011,0 & 819,0 \\
Audiovisual & 33,70 & 844,5 & \\
Demonstrasi & 27,30 & 985,5 & \\
\hline Diskusi & 28,15 & & \\
Demonstrasi & 32,85 & &
\end{tabular}

Sumber: Data primer, 2020

Pada tabel 6 didapatkan hasil bahwa selisih skor pengetahuan antara kelompok leaflet vs audiovisual berbeda secara bermakna, dengan mean rank kelompok 
leaflet lebih rendah dibandingkan dengan mean rank kelompok leaflet $(20,28$ vs 40,72; $\mathrm{P}=0,000$ ). Pada perbandingan selisih skor kelompok leaflet vs diskusi juga ditemukan adanya perbedaan signifikan dengan mean rank lebih tinggi pada kelompok diskusi $(24,65$ vs 36,35 ; $\mathrm{P}=0,009$ ). Demikian halnya pada perbandingan selisih skor antara kelompok leaflet dan demonstrasi dengan mean rank lebih tinggi pada demonstrasi $(23,42$ vs 37,58; $\mathrm{P}=0,002)$. Hasil signifikan juga terlihat pada perbandingan selisih skor antara kelompok audiovisual vs diskusi dengan mean rank lebih tinggi pada kelompok audiovisual (36,23 vs 24,77; $\mathrm{P}=0,010$ ). Sementara pada perbandingan antara audiovisual vs demonstrasi dan diskusi vs demonstrasi tidak ada perbedaan bermakna $(\mathrm{P}>0,05)$.

\section{PEMBAHASAN}

\section{Karakteristik responden}

Penelitian melibatkan 120 responden yang dibagi menjadi 4 kelompok perlakuan. Berdasarkan hasil uji homogenitas varians, karakteristik ibu yang sama pada semua kelompok adalah umur (dengan median 29 tahun) dan pengetahuan ibu sebelum diberikan penyuluhan tatalaksana diare. Adapun tingkat pendidikan, penghasilan, pengalaman menangani balita diare, akses informasi serta sikap ibu sebelum diberi penyuluhan tatalaksana diare tidak homogen. Informasi mengenai tatalaksana diare bisa diperoleh baik dari penyuluhan, membaca informasi dari media cetak, diberi tahu orang lain maupun dari media elektonik seperti TV, gadget dan lainnya.

Karakteristik responden yang mayoritas berusia 21-35 tahun dan bekerja sebagai ibu rumah tangga sama dengan karakteristik responden pada penelitian gambaran pengetahuan ibu balita tentang penangan awal balita diare di Kabupaten Gowa.(Safiyanthy et al., 2018) Sebagaimana yang diketahui bahwa usia 21-35 merupakan usia ideal dan paling aman yang disarankan untuk proses reproduksi. Pada penelitian ini, semua responden pada kelompok yang mendapat perlakuan diskusi memiliki pendapatan yang <2 juta perbulan, sedangkan kelompok yang paling sedikit memiliki pendapatan <2 juta perbulan adalah kelompok leaflet dengan jumlah $80 \%$.

\section{Perbedaan Pengetahuan dan Sikap Responden Sebelum dan Setelah Intervensi Berdasarkan Kelompok Perlakuan}

Berdasarkan tabel 2 dapat diketahui bahwa adanya penyuluhan dapat meningkatkan skor pengetahuan dan sikap secara signifikan. Perbedaan signifikan skor sebelum dan setelah pemberian intervensi penyuluhan juga ditemukan pada penelitian Andarmoyo (2015) tentang pengaruh leaflet terhadap pengetahuan penderita TB dengan nilai mean skor yang meningkat dari 6,60 menjadi 8,30 dengan $\mathrm{P}=0,001$. Hasil yang sama juga pada penelitian tentang pengaruh leaflet terhadap pengetahuan dan Sikap Periksa Payudara Sendiri (SADARI) pada akseptor KB hormonal dengan perbedaan skor mean rank pengetahuan sebesar 26,50 $(\mathrm{P}=0,007)$ dan pada sikap sebesar 27,28 ( $\mathrm{P}=0,024)$ (Mulyati \& Winancy, 2019). Pengaruh leaflet ini juga dikuatkan oleh penelitian Tindaon (2018) yang menunjukkan bahwa leaflet dapat meningkatkan rata-rata skor pengetahuan kelompok dari 4,60 menjadi $7,33(\mathrm{P}=0,000)$ dan skor sikap dari 42,90 menjadi $46,00(\mathrm{P}=0,000)$.

Perbedaan skor sebelum dan setelah edukasi kesehatan dengan menggunakan video juga ditemukan pada penelitian pengaruh video terhadap pengetahuan dan sikap pencegahan diare yang dilakukan oleh J et al (2019) dan Romlah et al. (2020); pengaruh video terhadap pengetahuan sikap tentang bahaya merokok oleh Siregar et al. (2019) dan pengaruh video terhadap pengetahuan kesehatan reproduksi oleh Djannah et al. (2020); pengaruh video terhadap sikap pencegahan hipertensi oleh Wahyuni et al. (2019). Pada 
penelitian Wahyuni et al. (2019), ditemukan hasil yang sedikit berbeda, bahwa tidak ada perbedaan signifikan sebelum dan setelah dilakukan intervensi audiovisual terhadap pengetahuan tentang pencegahan hipertensi. Menurut Susilowati (2016), audiovisual cocok untuk meningkatkan sikap karena audiovisual berisi gambar dengan suara yang dapat memberikan contoh real sehingga menggugah jiwa, emosi dan sikap seseorang.

Pada penelitian ini metode diskusi meningkatkan skor pengetahuan dan sikap tatalaksana diare secara signifikan. Hasil ini diperkuat dengan studi yang menemukan adanya perbedaan skor pengetahuan dan sikap ibu hamil tentang pencegahan makrosomia di Mandailing Natal sebelum dan setelah diberi edukasi dengan metode diskusi (Noviyanti, 2020). Diskusi juga ditemukan berpengaruh terhadap peningkatan pengetahuan dan sikap santriwati tentang kebersihan diri sebelum dan setelah dilakukan diskusi $(\mathrm{P}=0,000)$ (Asrina, 2019). Metode diskusi dapat memudahkan fasilitator dan peserta penyuluhan kesehatan untuk dapat saling berbagi informasi dan pengalaman satu sama lain sehingga diskusi bisa menambah pengetahuan yang baru. Diskusi yang menarik bisa membuat peserta untuk mencapai tahapan sikap receiving dan responding terutama pada bagian tanya jawab terkait materi (Asrina, 2019).

Hasil penelitian ini menunjukkan adanya peningkatan skor pengetahuan dan sikap setelah demosntrasi diberikan. Hasil ini juga memperkuat teori bahwa demonstrasi dapat menjadi pilihan untuk meningkatkan skor pengetahuan dan sikap responden terkait tatalaksana diare. Demonstrasi ditemukan dapat meningkatkan peringkat rata-rata kelompok skor pengetahuan dan sikap masing-masing sebesar 38,50 dan 37,72 (Mulyati \& Winancy, 2019). Adanya pengaruh metode demonstrasi terhadap pengetahuan juga dikuatkan oleh penelitian Stauri et al.
(2016) dengan simpulan metode demonstrasi memberikan pengaruh signifikan terhadap peningkatan skor pengetahuan responden. Menurut Rianto (2006) sebagaimana yang dikutip Stauri et al (2016), metode demonstrasi dapat mengurangi kesalahan penafsiran peserta didik dibandingkan dengan jika hanya membaca dan mendengar, melibatkan peserta dalam berbuat, lebih memusatkan perhatian peserta terhadap materi yang penting, dan memungkinkan peserta untuk segera bertanya terakit materi yang diperagakan. Sebagaimana audiovisual, demonstrasi juga dikatakan cocok untuk meningkatkan sikap karena demonstrasi dapat memberikan contoh real yang dapat menggugah jiwa, emosi dan sikap seseorang (Susilowati, 2016).

Berdasarkan tabel 4, disimpulkan bahwa kelompok leaflet memiliki peringkat rata-rata yang paling tinggi dibandingkan dengan kelompok lainnya, sebaliknya demonstrasi memiliki peringkat rata-rata yang paling rendah jika dibandingkan dengan ketiga kelompok perlakuan lainnya. Hasil ini tidak sejalan dengan hasil penelitian Trifitriana et al. (2020) yang menunjukkan bahwa audiovisual efektif untuk meningkatkan pemahaman siswa sekolah dasar tentang penyakit TB dengan hasil post-test sebesar $87,9 \%$ dan hasil ini lebih efektif dibandingkan dengan metode ceramah dengan tingkat pemahaman $83,0 \%$ $(\mathrm{P}=0,000)$ (Trifitriana et al., 2020). Selain itu, pada perbandingan skor pengetahuan antara kelompok audiovisual vs demonstrasi tidak ditemukan adanya perbedaan yang signifikan dengan nilai $\mathrm{P}=0,108$.

Tingginya skor pengetahuan dan sikap kelompok leaflet pada post-test ini bisa jadi disebabkan karena skor nilai pengetahuan dan sikap kelompok leaflet pada pre-test memang jauh lebih tinggi dibandingkan dengan skor kelompok lainnya. Pada tabel 1 juga diketahui bahwa pada kelompok leaflet terdapat lebih banyak responden yang berpendidikan tinggi, bekerja di luar 
rumah dan memiliki penghasilan yang lebih tinggi sehingga nilai pre-testnya lebih tinggi. Pendidikan tinggi, pekerjaan luar rumah dan penghasilan yang tinggi secara signifikan berpengaruh terhadap pengetahuan dan sikap manajemen tatalaksana diare balita (Amare \& Mullu, 2015; Desta et al., 2017; Mathiazhakan, 2016; Merali et al., 2018). Meski demikian, salah satu kelebihan leaflet sebagai media edukasi adalah leaflet yang menggunakan pesan berupa poin-poin singkat, gambar dan warna yang menarik serta dapat dibuka kembali untuk belajar mandiri, sehingga cocok digunakan untuk pendidikan kesehatan yang bertujuan mengubah tingkat pengetahuan (Susilowati, 2016).

\section{Perbedaan Skor Pengetahuan Dan Sikap Responden Berdasarkan Nilai Post-Test}

Berdasarkan perbedaan hasil skor posttest pengetahuan dan sikap responden, diketahui ada perbedaan skor pengetahuan dan sikap responden setelah penyuluhan tatalaksana diare balita antara kelompok yang diberi leaflet, audiovisual, diskusi dan demonstrasi. Selain itu, kelompok leaflet memiliki peringkat rata-rata yang paling tinggi dibandingkan dengan kelompok lainnya, sebaliknya demonstrasi memiliki peringkat rata-rata yang paling rendah jika dibandingkan dengan ketiga kelompok perlakuan lainnya. Hasil ini tidak sejalan dengan hasil penelitian Trifitriana et al. (2020) yang menunjukkan bahwa audiovisual efektif untuk meningkatkan pemahaman siswa sekolah dasar tentang penyakit TB dengan hasil post-test sebesar $87,9 \%$ dan hasil ini lebih efektif dibandingkan dengan metode ceramah dengan tingkat pemahaman $83,0 \%$ $(\mathrm{P}=0,000)$.(Trifitriana et al., 2020) Selain itu, pada perbandingan skor pengetahuan antara kelompok audiovisual vs demonstrasi tidak ditemukan adanya perbedaan yang signifikan dengan nilai $\mathrm{P}=0,108$.

Hasil penelitian ini juga menunjukkan adanya perbedaan skor sikap yang signifikan pada perbandingan antara kelompok leaflet vs audiovisual; leaflet vs diskusi; dan leaflet vs demonstrasi. Pada perbandingan skor post-test tersebut leaflet terbukti memiliki nilai peringkat rata-rata yang lebih tinggi baik ketika dibandingkan dengan kelompok audiovisual, diskusi maupun demonstrasi. Sebaliknya, kelompok audiovisual selalu memiliki nilai peringkat rata-rata yang lebih rendah jika dibandingkan dengan ketiga kelompok lainnya. Pada perbandingan skor sikap antara kelompok audiovisual vs diskusi; audiovisual vs demonstrasi dan diskusi vs demonstrasi tidak ditemukan adanya perbedaan signifikan $(\mathrm{P}=0,428 ; \mathrm{P}=0,053$; $\mathrm{P}=0,364$ ).

Tingginya skor pengetahuan dan sikap kelompok leaflet pada post-test ini bisa jadi disebabkan karena skor nilai pengetahuan dan sikap kelompok leaflet pada pre-test memang jauh lebih tinggi dibandingkan dengan skor kelompok lainnya. Pada tabel 1 juga diketahui bahwa pada kelompok leaflet terdapat lebih banyak responden yang berpendidikan tinggi, bekerja di luar rumah dan memiliki penghasilan yang lebih tinggi sehingga nilai pre-testnya lebih tinggi. Pendidikan tinggi, pekerjaan luar rumah dan penghasilan yang tinggi secara signifikan berpengaruh terhadap pengetahuan dan sikap manajemen tatalaksana diare balita.(Amare \& Mullu, 2015; Desta et al., 2017; Mathiazhakan, 2016; Merali et al., 2018) Meski demikian, salah satu kelebihan leaflet sebagai media edukasi adalah leaflet yang menggunakan pesan berupa poin-poin singkat, gambar dan warna yang menarik serta dapat dibuka kembali untuk belajar mandiri, sehingga cocok digunakan untuk pendidikan kesehatan yang bertujuan mengubah tingkat pengetahuan.(Susilowati, 2016)

\section{Perbedaan Skor Pengetahuan Dan Sikap Responden Berdasarkan Selisih Nilai Pre-Test Dan Post-Test}

Hasil penelitian menunjukkan adanya perbedaan yang signifikan efektivitas 
penyuluhan menggunakan media leaflet, audiovisual, diskusi dan demonstrasi dalam meningkatkan pengetahuan responden tentang tatalaksana balita diare. Berdasarkan mean rank hasil perbedaan selisih skor pre dan post-test tabel 5, selisih mean rank audiovisual yang lebih tinggi (lebih efektif) dibandingkan demonstrasi, diskusi dan leaflet untuk meningkatkan pengetahuan tatalaksana diare pada balita di Kota Palopo. Akan tetapi, perbedaan efektivitas masing-masing media dan metode tersebut tidak ditemukan terhadap perbedaan peningkatan selisih mean rank sikap responden dalam tatalaksana diare pada balita.

Hasil tersebut dikuatkan dengan uji Mann Whitney pada tabel 6 yang menunjukkan bahwa, mean skor kelompok audiovisual selalu terlihat lebih tinggi jika dibandingkan ketiga kelompok lainnya sedangkan mean rank kelompok leaflet yang paling rendah dibandingkan kelompok lainnya, dengan kata lain penyuluhan dengan audiovisul lebih efektif dibandingkan dengan leaflet, diskusi dan demonstrasi. Hasil studi ini sama dengan hasil penelitian Waryana et al. (2019) yang menemukan adanya pengaruh pemberian media video terhadap perubahan pengetahuan remaja putri dalam mencegah kurang energi kronik $(\mathrm{P}=0,000)$.(Waryana et al., 2019) Hasil ini juga diperkuat oleh penelitian Tindaon (2018) bahwa media video lebih efektif meningkatkan pengetahuan dan sikap dibandingkan leaflet.(Tindaon, 2018)

Pemberian edukasi tatalaksana diare balita di tatanan rumah tangga oleh tenaga kesehatan perlu dilakukan. Berdasarkan sistematic review tentang praktik tatalaksana diare yang berbahaya di negaranegara berpenghasilan menengah ke bawah oleh Carter et al. (2015) didapatkan fakta bahwa meskipun pengasuh balita sudah berupaya untuk memberikan yang terbaik sesuai dengan pengetahuan dan kemampuannya, namun masih banyak yang melakukan tindakan berbahaya seperti pembatasan asupan cairan, ASI atau makanan tambahan selama episode diare serta penggunaan obat-obatan/ antibiotik yang tidak seharusnya.(Carter et al., 2015) Padahal tindakan yang berbahaya tersebut dilakukan berdasarkan nasehat tenaga kesehatan, anggota komunitas serta keluarga yang lebih tua atau mengikuti kepercayaan secara turun-temurun untuk kasus diare yang spesifik. Oleh karenanya, tenaga kesehatan perlu berupaya untuk memberikan edukasi tatalaksana diare balita yang sesuai dengan rekomendasi WHO.

Audiovisual dapat menjadi pilihan tenaga kesehatan dalam memberikan edukasi kesehatan, terutama kepada ibu muda yang masih kurang pengalaman dalam tatalaksana diare balita karena media audiovisual memiliki beberapa kelebihan, diantaranya lebih mudah dipahami, lebih menarik dan menyertakan seluruh pancaindera, sehingga efeknya lebih besar (Susilowati, 2016). Selain itu, media audiovisual akan menjadi sesuatu yang baru karena media promosi yang digunakan di fasilitas kesehatan selama ini adalah leaflet, sehingga di era digital seperti sekarang media audiovisual dipandang lebih menarik dan lebih kekinian terutama bagi ibu muda. Merujuk pada tulisan Shamsideen (2016), audiovisual dianggap penting dalam pembelajaran karena audiovisual dapat memperpanjang pengalaman, mendorong partisipasi, menarik perhatian, pengajaran yang dapat dilakukan secara individual, menjadi sumber informasi, dan menjadikan proses pembelajaran yang lebih permanen. (Shamsideen, 2016) Menurut Dike (1993) sebagaimana yang disitasi Shamsideen (2016), ketika suatu fenomena divisualisasikan, gambar dan pengetahuan akan menajdi lebih jelas dan permanen sebagaimana pepatah mengatakan satu gambar lebih bermakna dibandingkan seribu kata.(Shamsideen, 2016)

Efektivitas media audiovisual dalam meningkatkan pengetahuan ibu tentang 
tatalaksana diare di Kota Palopo ini diperkuat dengan hasil penelitian Conceicao (2017) yang menyimpulkan video berdurasi pendek cukup efektif untuk meningkatkan pengetahuan yang bersifat jangka pendek.(Conceição et al., 2017). Pada penelitian ini, post-test dilakukan sesaat setelah intervensi diberikan, sehingga untuk mengetahui efek audiovisual terhadap pengetahuan jangka panjang masih perlu dikaji. Selain itu, intervensi yang dilakukan pada penelitian ini adalah intervensi individu, sehingga efek diskusi yang diberikan mungkin akan berbeda jika dilakukan dengan diskusi kelompok kecil.

\section{KESIMPULAN}

Ada perbedaan skor pengetahuan dan sikap yang signifikan sebelum dan setelah intervensi tatalaksana diare balita di rumah tangga dengan menggunakan leaflet, audiovisual, diskusi dan demonstrasi. Berdasarkan perbedaan peningkatan skor pre-test post-test, ada perbedaan peningkatan skor pengetahuan yang signifikan diantara keempat perlakuan dengan nilai mean skor paling tinggi pada kelompok audiovisual, artinya audiovisual lebih efektif untuk meningkatkan pengetahuan ibu balita diare di Palopo dibandingkan media dan metode lainnya. Berdasarkan selisih skor pre-test post-test, tidak ada perbedaan signifikan pada peningkatan skor sikap diantara keempat kelompok perlakuan. Pada penelitian ini, post-test dilakukan sesaat setelah intervensi diberikan, sehingga untuk mengetahui efek audiovisual terhadap pengetahuan jangka panjang masih perlu dikaji.

\section{UCAPAN TERIMAKASIH}

Peneliti mengucapkan terima kasih kepada Kementerian Riset dan Teknologi Republik Indonesia atas bantuan dana hibah penelitian dosen pemula untuk semua proses pelaksanaan penelitian ini. Terima kasih juga kepada semua kepala puskesmas beserta staffnya se-Kota Palopo serta semua pihak yang telah membantu dalam proses penelitian ini.

DAFTAR PUSTAKA

Amare, D., \& Mullu, G. (2015). Mothers' Attitude Towards Childhood Diarrhea Management and Prevention in Under Five Children in Fenote Selam Town, West Gojjam, Amhara, Northwest Ethiopia. Science Journal of Public Health, 3(3), 398-403.

Andarmoyo, S. (2015). Pemberian Pendidikan Kesehatan Melalui Media Leaflet Efektif Dalam Peningkatan Pengetahuan Perilaku Pencegahan Tuberkulosis Paru di Kabupaten Ponorogo. Prosiding Seminar Nasional Pendidikan; Inovasi Pembelajaran untuk Pendidikan Berkemajuan, 6.

Asrina, A. (2019). Pengaruh Metode Diskusi Terhadap Pengetahuan dan Sikap Tentang Kebersihan Diri. Prosiding Semiar Nasional Sinergitas Multidisiplin Ilmu Pengetahuan dan Teknologi, 2, 4853.

Badan Pusat Statistik Kota Palopo. (2018). Kota Palopo Dalam Angka 2018. BPS Kota Palopo.

Carter, E., Bryce, J., Perin, J., \& Newby, H. (2015). Harmful practices in the management of childhood diarrhea in low- and middle-income countries: A systematic review. BMC Public Health, 15(1), 788. https://doi.org/10.1186/s12889-0152127-1

Conceição, C., Pedro, J., \& Martins, M. V. (2017). Effectiveness of a video intervention on fertility knowledge among university students: A randomised pre-test/post-test study.

The European Journal of Contraception \& Reproductive Health Care, 22(2), 107-113.

Desta, B. K., Assimamaw, N. T., \& Ashenafi, T. D. (2017). Knowledge, 
Practice, and Associated Factors of Home-Based Management of Diarrhea among Caregivers of Children Attending Under-Five Clinic in Fagita Lekoma District, Awi Zone, Amhara Regional State, Northwest Ethiopia, 2016. Nursing Research and Practice, 2017, 1-8. https://doi.org/10.1155/2017/80845 48

Djannah, S. N., Sulistyawati, S., Sukesi, T. W., Mulasari, S. A., \& Tentama, F. (2020). Audio-visual media to improve sexual-reproduction health knowledge among adolescent. International Journal of Evaluation and Research in Education (IJERE), $\quad 9(1), \quad 138$. https://doi.org/10.11591/ijere.v9i1.2 0410

J, H., Oktavidiati, E., \& Astuti, D. (2019). Pengaruh Pendidikan Kesehatan Media Video dan Poster terhadap Pengetahuan dan Sikap Anak dalam Pencegahan Penyakit Diare. Jurnal Kesmas Asclepius, 1(1), 75-85. https://doi.org/10.31539/jka.v1i1.74 7

Kemenkes Republik Indonesia. (2011). Panduan Sosialisasi Tatalaksana Diare Balita. Kementerian Kesehatan RI. https://agus34drajat.files.wordpress. com/2010/10/buku-panduansosialisasi-tata-laksana-diare-balita2011.pdf

Kemenkes Republik Indonesia. (2019). Laporan Nasional Riskesdas 2018. Lembaga Penerbit Badan Penelitian dan Pengembangan Kesehatan. http://labdata.litbang.kemkes.go.id/c count/click.php?id=19

Kemenkes RI. (2020). Profil Kesehatan Indonesia Tahun 2019. Kementerian Kesehatan RI. https://www.kemkes.go.id/resources /download/pusdatin/profilkesehatan-indonesia/ProfilKesehatan-Indonesia-2019.pdf
Mathiazhakan, U. (2016). A Study to Assess The Knowledge, Attitude and Practice of Caregiver of Children Admitted With Diarrhoea at $\mathrm{KMCH}$ Hospital Coimbatore. International Journal of Pharmacy and Biological Sciences, 7.

Merali, H. S., Morgan, M. S., \& Boonshuyar, C. (2018). Diarrheal knowledge and preventative behaviors among the caregivers of children under 5 years of age on the Tonle Sap Lake, Cambodia. Research and Reports in Tropical Medicine, Volume 9, 35-42. https://doi.org/10.2147/RRTM.S156 702

Mulyati, S., \& Winancy, W. (2019). Effect of Health Education Demonstration Method and Leaflet Media about Consciousness on Knowledge and Attitude of Hormonal KB Acceptors. Jurnal Ilmu Dan Teknologi Kesehatan, 7(1), 60-67. https://doi.org/10.32668/jitek.v7i1.2 17

Noviyanti, R. (2020). Pengaruh Metode Ceramah dan Diskusi Terhadap Pengetahuan dan Sikap Ibu Hamil Tentang Pencegahan Makrosomia di Puskesmas Siabu Kabupaten Mandailing Natal Tahun 2016. Jurnal Ilmiah Kebidanan Imelda, 6(1), 61-67.

Priyatno, D. (2016). Belajar Alat Analisis Data dan Cara Pengolahahannya dengan SPSS. Penerbit Gava Media. Romlah, S. N., Puspita, R. R., \& Ratnasari, D. (2020). Pendidikan Kesehatan dengan Media Video Mempengaruhi Pengetahuan dan Sikap Anak dalam Pencegahan Penyakit Diare. Jurnal Kesehatan Pertiwi, 2(1), 118-124.

Rosalia, L. (2016). Hubungan Tingkat Pengetahuan Ibu dengan Penatalaksanaan Awal Diare pada Balita di Puskesmas Piyungan Bantul Yogyakarta. 
Digilib2.Unisayogya.Ac.Id. http://digilib2.unisayogya.ac.id/han dle/123456789/2268

Safiyanthy, I., Wong, A., \& Mukarramah, S. (2018). Gambaran Pengetahuan Ibu Balita Dalam Penanganan Awal Balita Diare di Desa Bone Kec. Bajeng Kab. Gowa Tahun 2017. Jurnal Bidan, 4(01), 1-7.

Shamsideen, S. A. (2016). Impact of audiovisual materials in the dissemination of knowledge for facilitators in some selected literacy centres in Oshodi/Isolo Local Government Area. African Educational Research Journal, 4(1), 19-24.

Siregar, S., Rochadi, K., \& Maas, L. T. (2019). The Effect of Audio-Visual Media on adolescents' Knowledge and attitude Toward Smoking Dangerous at secondary High School 2 Halongonan Subdistrict, Indonesia. International Journal of Nursing and Health Services (IJNHS), 2(3), 164-171. https://doi.org/10.35654/ijnhs.v2i3. 147

Stauri, S., Rasni, H., \& Wantiyah. (2016). Pengaruh Pendidikan Kesehatan Metode Demonstrasi terhadap Tingkat Pengetahuan dan Motivasi Penggunaan Alat Pelindung Diri (APD) pada Petani Desa Wringin Telu Kecamatan Puger Kabupaten Jember. e-Jurnal Pustaka Kesehatan, 4(1), 95-101.

Susilowati, D. (2016). Modul Bahan Ajar Cetak Keperawatan: Promosi Kesehatan. BPPSDMK Kementerian Kesehatan RI. http://bppsdmk.kemkes.go.id/pusdik sdmk/wpcontent/uploads/2017/08/PromkesKomprehensif.pdf

Tindaon, R. L. (2018). Pengaruh Komunikasi, Informasi, Dan Edukasi (KIE) Melalui Media Leaflet dan Video Terhadap Pengetahuan dan sikap Remaja
Tentang Paparan Pornografi di SMP Negeri 1 Sidamanik Kec. Sidamanik Kab. Simalungun Tahun 2016. Jumantik, 3(1), 44-64.

Trifitriana, M., Fadilah, M., \& Mulawarman, R. (2020). Effectiveness of Health Promotion Through Audiovisual Media and Lecture Methods on the Level of Knowledge in Elementary School Children About TB Disease. Medicinus, 7(6), 174-183. https://doi.org/10.19166/med.v7i6.2 595

Wahyuni, A. S., Amelia, R., Nababan, I. F. F., Pallysater, D., \& Lubis, N. K. (2019). The Difference of Educational Effectiveness Using Presentation Slide Method with Video About Prevention of Hypertension on Increasing Knowledge and Attitude in People with the Hypertension Risk in Amplas Health Center. Open Access Macedonian Journal of Medical Sciences, 7(20), 3478-3482. https://doi.org/10.3889/oamjms.201 9.450

Waryana, W., Sitasari, A., \& Febritasanti, D. W. (2019). Intervensi Media Video Berpengaruh pada Pengetahuan dan Sikap Remaja Putri dalam Mencegah Kurang Energi Kronik. Jurnal AcTion: Aceh Nutrition Journal, 4(1), 58-62.

World Health Organization. (2017). Diarrhoeal disease. WHONewsroom-Fact Sheet Diarrhoeal Disease. https://www.who.int/newsroom/fact-sheets/detail/diarrhoealdisease

Zain, R. S. M., Primanagara, R., Naldi, Y., \& Nurbaiti, N. (2020). The Influence of Giving Information on Diarrhea Management to the Knowledge and Attitude of the Mother Carrying Infants in the Primary Health Care in Sitopeng Cirebon. Proceedings of the 
International Conference on Agriculture, Social Sciences, Education, Technology and Health (ICASSETH 2019). International Conference on Agriculture, Social
Sciences, Education, Technology and Health (ICASSETH 2019), Cirebon, Indonesia. https://doi.org/10.2991/assehr.k.200 402.066 